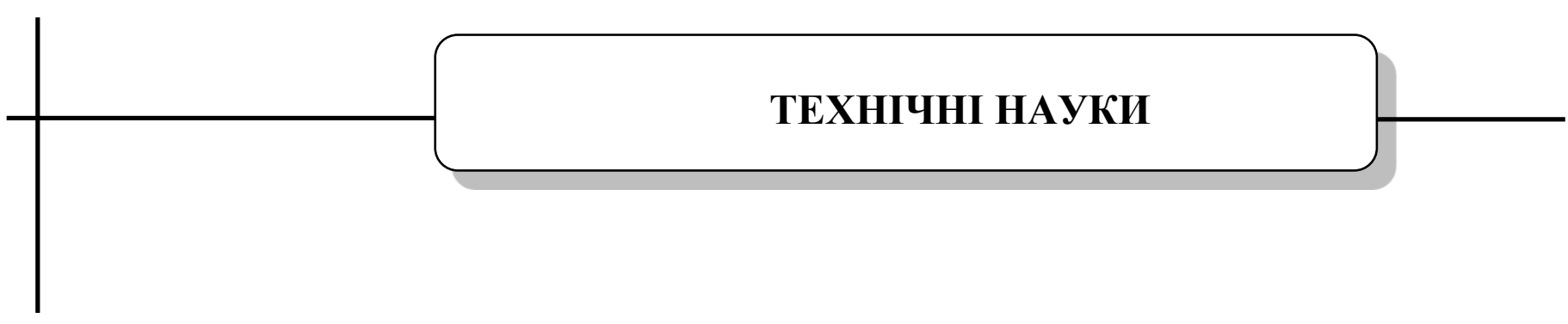

УДК 006:658.8

DOI: 10.15587/2313-8416.2018.143414

\title{
ANALYSIS OF A SEMICONDUCTOR VIBRATION AND FREQUENCY SENSOR CONSTRUCTION SPECIFITY
}

\author{
(C) R. Baitsar, R. Kvit
}

Описана модель тензорезистивного способу прямого перетворення механічних коливань напівпровідникового монокристала в електричний сигнал і принцип побудови перетворювача (сенсора) деформації в частоту. Встановлено зв'язки параметрів вихідного тензосигналу з власними геометричними розмірами резонатора механічним напруженням та пружністю кристалів, амплітудою $і$ частотою їх механічних коливань. Очінено величину тензосигналу, який виникає внаслідок згину і розтягу монокристалів в умовах циклічних навантажень, виявлено специфіку їх властивостей і структури

Ключові слова: напівпровідник, ниткоподібний монокристал, тензоперетворювач, резонатор, частота, чутливий елемент, тензосигнал, деформація

\section{Introduction}

Modern trends in measuring technology are characterized by the wide introduction of semiconductors, miniaturization of elements and nodes, and their unification. With regard to sensor electronics, these trends are realized through the using of semiconductor materials and structures to create sensitive elements based on new principles and technologies. It allows effectively solve problematic issues of information and measuring technologies of automation and instrument making. New severer requirements for measuring transducers, along with significantly increased information flow generate a need for digital computing techniques and new designing opportunities for sensors, the output signal of which is integrated with an input of computing complexes. A promising object of research and implementation are filamentous monocrystals that, due to their structural perfection, morphology and dimensions, are the ideal elemental base for the creation of various sensors.

\section{Literature review}

The analysis of references indicated that the resonant transducers containing high-quality mechanical vibration system have the widest practical usage. Comparing with other types of frequency transducers the resonant once have a number of significant advantages [1, 2]. A method of active frequency tuning on comb-shape microresonators has been successfully demonstrated by means of localized stressing effects [3]. In article [4] the design of a two-port ring microelectromechanical resonator with electrothermal actuation and piezoelectric sensing is discussed. A brief overview of the resonance behavior and frequency tuning principles by varying either the mass or the stiffness of resonators is presented in [5]. A monolithic resonance frequency readout circuit with high resolution and short measurement time is reported in [6].

The application of semiconductor materials with tensoresistive (piezoresistive) properties opens new possibilities in the development of measuring transducers $[7,8]$.

Perspective for the creation of electromechanical resonators of vibration and frequency transducerss is the using of semiconductor filamentous monocrystals (FMCs) [9, 10]. The structure thoroughness and related thoroughness of their physical and mechanical properties enables considering the FMCs as a mechanical environment, strength and elastic properties of which are best suited for the vibration system with maximum possible Q-value, stability and reliability. Furthermore, semiconductor FMCs show a significant piezoresistive effect, that enables the using of their electrophysical properties for excitation of mechanical vibrations. As a rule, the choice of a string substance defines the choice of a vibration excitation system. Certain advantages are provided by electrostatic method for excitation of FMC's mechanical vibrations. It delivers exceptional comforts for designing of vibration frequency transducers based on a string variant of the tensoresistive measuring method.

\section{The aim and objectives of research}

The aim of research is creation a vibration and frequency sensor with improved metrological characteristics, designed to measure deformation or other physical value reduced to deformation.

To achieve this aim, the following tasks need to be solved: 
- explore physical and mathematical models of direct transformation of mechanical vibrations of a monocrystal into electric;

- choose the material of a monocrystal sensitive element and to establish a relationship between its parameters and factors that provide them;

- carry out of the resonator layout, to confirm the results of theoretical studies, to substantiate the requirements to the scheme of the excitation of its mechanical oscillations.

\section{Model and principle of vibration and fre- quency sensor construction}

Using $\mathrm{Si}$ and $\mathrm{Si}-\mathrm{Ge}$ monocrystals as the oscillators, it is possible to more fully realize the fundamental advantages of frequency transducers with mechanical resonators (Fig. 1).

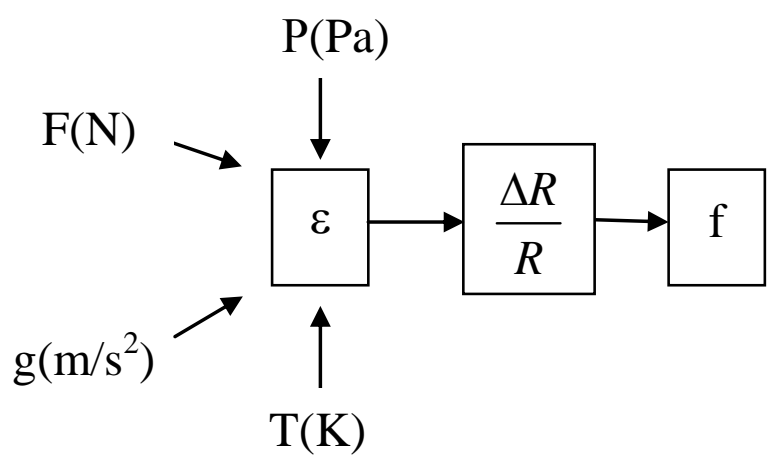

Fig. 1. Tensoresistive principle of converting mechanical vibrations of semiconductor FC into the frequency

Firstly, a direct transformation of mechanical vibrations into electrical vibrations inside of a vibrating crystal precludes the using of any other special transforming devices (add-on elements) that simplifies significantly the design of the transducer, enhances its reliability and metrological quality. Secondly, elevated elastic properties of crystals, absence of their plastic deformation and hysteresis enable achieving of much higher values of sensitivity and results reproducibility. Thirdly, local fixing of crystal's ends in mounting points enables using of short and thin filaments, which provides maximum sensitivity. Since FMCs are able to maintain their elastic properties almost up to ultimate strength boundary, the deformation measurement range is essentially extended.

In modelling operation of a frequency vibration tensotransducer the FMC was considered in the form of a thin elastic string with rigidly fixed ends (Fig. 2), neglecting energy losses in mounting points and considering only the environment resistance. Such approximation is justified by the rigidity of FMC's fixing by means of glass-ceramic cements.

An alternating voltage is generated between the Crystal 1 and the exciting electrode (EE) 2 that results in arising of the electrostatic interaction force:

$$
P=\frac{c^{2} U^{2}}{4 \pi \varepsilon_{0} b^{2}} \sin ^{2} \omega t=p_{0}(1-\cos 2 \omega t),
$$

where .. is the distance between FMC and EE; $c$ is the system FMC-EE capacity; $\varepsilon_{0}$ is the absolute dielectric constant. This force is a gravity force, which consists of the constant component $P_{0}$ and the variable harmonic component $P_{0} \cos 2 \omega t$.

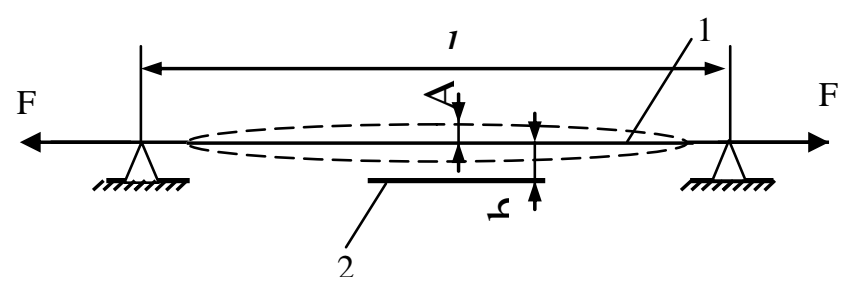

Fig. 2. Scheme of the operation of electromechanical resonator-tensotransducer with FC electrostatic excitement

Under the action of the harmonic exciting force, the sinusoid harmonic vibrations are established in the crystal. The transverse vibration equation of the crystal can be written as following:

$$
y(x, t)=\frac{4 P}{n \pi \mu \omega_{0}} \sin \omega_{0} t \cdot \sin \frac{n \pi x}{l},
$$

where $\omega_{0}$ is the basic frequency of FMC's natural vibrations (resonance condition); $n$ is the harmonic number; vibration amplitude and maximum deviation of the point $x$ at the moment of time $t$ :

$$
A=\frac{4 P}{n \pi \mu \omega_{0}}, \quad y_{m}(t)=\frac{4 P}{n \pi \mu \omega_{0}} \sin \omega_{0} t .
$$

The operating principle of the vibration frequency tensotransducer is based on a deformation of the FMC while vibrating, i.e. its length changes periodically. The total length of the crystal $l$ at any moment of time $t$ can be written as the sinusoid segment $A(t) \sin \pi x / l$ between the points $x=0, x=l_{0}$, for which the displacement $y=0$, where $A(t)=A_{0} \sin \omega_{0} t$.

Considering that the length $l$ of the curve $y=y(x, t)$ is defined by the integral:

$$
l=\int_{0}^{l_{0}} \sqrt{1+\left(\frac{\partial y}{\partial x}\right)^{2} \partial x}
$$

we find:

$$
l=l_{0}\left[1+\frac{\pi^{2} A^{2}(t)}{4 l^{2}}\right] .
$$

Hence, the relative elongation of the string (deformation) is as follows:

$$
\frac{\Delta l}{l}=\varepsilon=\frac{\pi^{2} A_{0}^{2}}{8 l^{2}}\left(1-\cos 2 \omega_{0} t\right) .
$$


Thus, the transverse vibrations of the crystal along with the initial constant deformation due to the tension inside of the crystal produce the harmonic component with the frequency equal to the doubled frequency of FMC's vibration and with the amplitude, which is proportional to the square ratio $A_{0} / l$. For the tensosensitive crystal the relative change of the resistance is directly proportional to the deformation:

$$
\Delta R / R_{0}=K \varepsilon,
$$

where $K$ is the tensosensitivity coefficient.

The variable component $\varepsilon$ causes a change of the crystal resistance in result of the tensoeffect:

$$
\Delta \tilde{R}=-\frac{\pi^{2} K A_{0}^{2}}{8 l^{2}} R_{0} \cos 2 \omega_{0} t
$$

If the string is fed with direct current $I_{0}$, the resistance vibrations result in voltage vibrations:

$$
\tilde{U}=-I_{0} R_{0} \frac{\pi^{2} K A_{0}^{2}}{8 l^{2}} \cos 2 \omega_{0} t .
$$

The frequency of this voltage can be defined using the known approximation formula for an ideal string:

$$
f=\frac{1}{2 l} \sqrt{\frac{\sigma}{\rho}},
$$

where $l$ is the string length; $\sigma$ is the mechanical stress inside the string (tensile force); $\rho$ is the substance density.

It is easily seen that at $\sigma_{\text {tension }} \approx 10^{9} \mathrm{~N} / \mathrm{m}^{2}$ for the FMC with minimum diameter $\sim 5 \mu \mathrm{m}$ the maximum value of its own frequency per unit length of the crystal is provided. The small value of semiconductor substance density ( $\rho=2,33 \cdot 10^{3} \mathrm{~kg} / \mathrm{m}^{3}$ for $\mathrm{Si}$ ) enables keeping vibrations active with minimum values of excitation energy.

The physical model of frequency vibration transducer (Fig. 3) contains:

1. Monocrystal elastic element, which senses a measurement value and transforms a surface deformation to the FMC. Almost total absence of the hysteresis $\left(\sim 10^{-9}\right.$ at $300^{\circ} \mathrm{C}$ in $\left.\mathrm{Si}\right)$ provides the replicability of a measurement result.

2. Vibrating element - an electromechanical resonator, which changes the frequency of its natural vibrations depending on the level of crystal deformation. In a proposed model the functions of vibrating and transducing components are combined in a single element - semiconductor FMC.

3. Exciting element in form of the electrode designed for supply of exciting alternating voltage. In this case, the surface of the piezoelectric element (PE) adjacent to the crystal is used as an exciting element.

4. The device for registration of signal frequency is a digital frequency meter with the class accuracy $\geq 10^{-4}$.

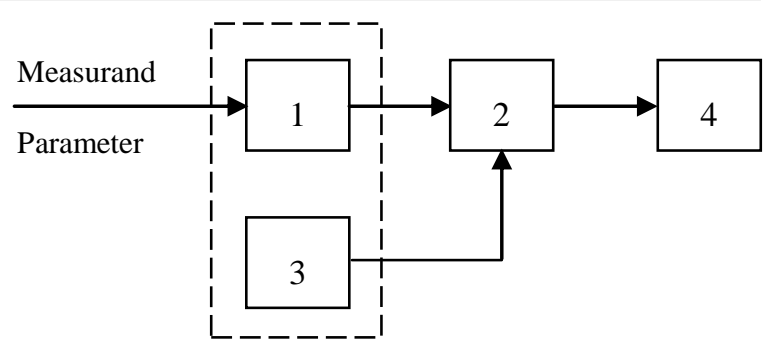

Fig. 3. Block diagram of semiconductor vibrationfrequency

The operation of the proposed tensotransducer is not significantly affected due to the temperature dependences of tensosensitivity factor and resistance, since the parameter to be measured is the vibration frequency, which is defined by the crystal geometry, its mechanical properties and applied force. The tensosensitivity of one such tensotransducer comes up to $10^{9} \mathrm{~Hz} /$ relative unit and it is one of the highest among the known semiconductor transducers.

The techniques developed for research of the FMCs under cyclic loads made it possible to define the specific nature of their properties and structure, increase sufficiently the stability and measurement accuracy of the output tensosignal parameters. The possibility of forced vibrations within crystals of different geometry while using magnetoelectric and electrostatic modes of excitation is studied (Fig. 4).

The optimal conditions of excitation and the influence of the FMC's ends fixing method on the vibration mode are defined. It has been established that the fixing of the FMCs by means of glass cements with mechanical and temperature properties, which are similar to the properties of the FMCs, is characterized by its manufacturability and ensures a durable connection. It has been determined that the most useful technique for excitation of mechanical vibrations within a crystal is an electrostatic one (Fig. 5). In modelling of the resonator operation in the function of a transducer, the dependence of the FMC's natural frequency vibration changes on the tensile force applied to it has been studied. The results of these researches indicate that the special feature of such resonator is a broad band of mechanical vibration frequency change under deformation and sufficient level of tensosignal amplitude.
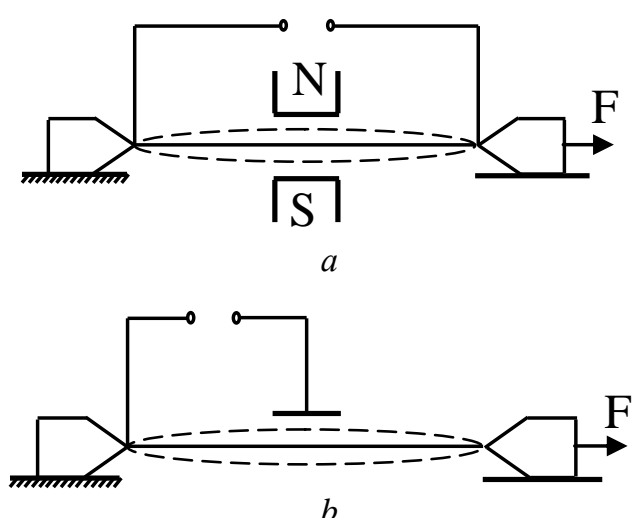

b

Fig. 4. Excitation methods of FC mechanical vibrations: $a$ - magnetoelectric; $b$ - electrostatic 


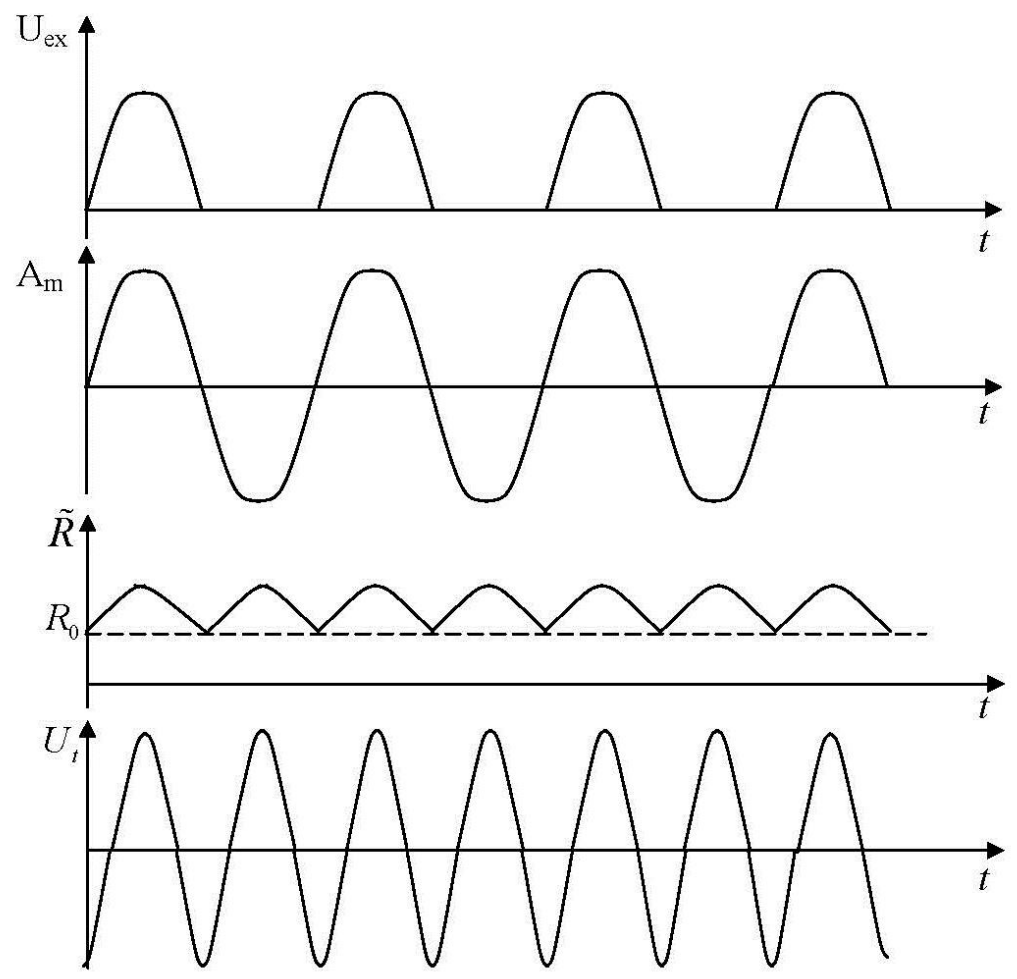

Fig. 5. Oscillogram of exciting pulses, amplitude of FC mechanical vibrations, alters of electric resistance and electrical signal

\section{Research results}

The value of the tensosignal, resulting from bending and stretching of the crystal while vibrating is estimated, the relationship between the parameters of this tensosignal and geometrical and elastic parameters of the FMCs, their axial stress, Q-value of the vibration system, amplitude, frequency and phase of mechanical vibrations are also established. It is determined that the relative change in crystal resistance:

$$
\frac{\Delta R^{\prime \prime}}{R_{0}^{\prime \prime}}=\frac{K^{2}}{4}\left(\frac{r}{l}\right)^{2}+\left(\frac{A}{l}\right)^{2} \int_{0}^{l}\left(\frac{d^{2} U_{0}}{d \xi^{2}}\right)^{2} d \xi
$$

is caused by its bending deformation under vibration and approximates to $10^{-4}$, variable integration $\xi=x / l, U_{0}$ is the function of crystal point deviation from the equilibrium position with maximum deviation equal to one, $A$ is the maximum deflection amplitude; $l, r$ are the length and radius of the crystal.

The relative change of crystal resistance due to its stretching under vibrations is proportional to the relative deformation:

$$
\frac{\Delta R^{\prime \prime}}{R_{0}^{\prime \prime}}=\frac{K}{2}+\frac{A^{2}}{l^{2}} \int_{0}^{l}\left(\frac{d^{2} U_{0}}{d \xi^{2}}\right)^{2} d \xi \approx 10^{-2} .
$$

Thus, in this case the resistance change is two orders higher. The change of the crystal resistance due to its bending and stretching is proportional to the squared amplitude of its vibrations. The most acceptable physical model for resonator calculation based on the FMC is an elastic homogeneous rod with fixed ends. The equation of natural transverse vibrations of such rod with due consideration of boundary conditions is as follows:

$$
1-\operatorname{ch} k \cdot \cos h+\frac{v^{2}}{2 \sqrt{\lambda}} \operatorname{sh} k \cdot \sin h=0 .
$$

For an unstrained rod, when $v^{2}=0$, the equation is simplified:

$$
1-\operatorname{ch} k \cdot \cos h=0 \text {. }
$$

The frequencies of the first harmonic components are defined by means of successive approximation. Some calculation results are provided in the Fig. 6 in form of diagrams indicating the dependency between frequency and mechanical stress $\sigma$ that affects the unit of the crystal cross-section area.

When $\sigma$ changing the change in frequency is greater for the short crystals and increases with decreasing of their diameter. This is due to the fact that when the decreasing of crystal diameter the vibrating element is similar in its properties to the ideal string, since its resisting bending moment (rigity decrease according to its diameter, and the ratio of strain force to the linear density at constant $\sigma$ is not related from the diameter. The detected linear dependence of natural frequency of FMC's vibrations from its diameter, approximately inversely proportional exponential dependence of this parameter from the length, confirms the correctness of the selected model. 


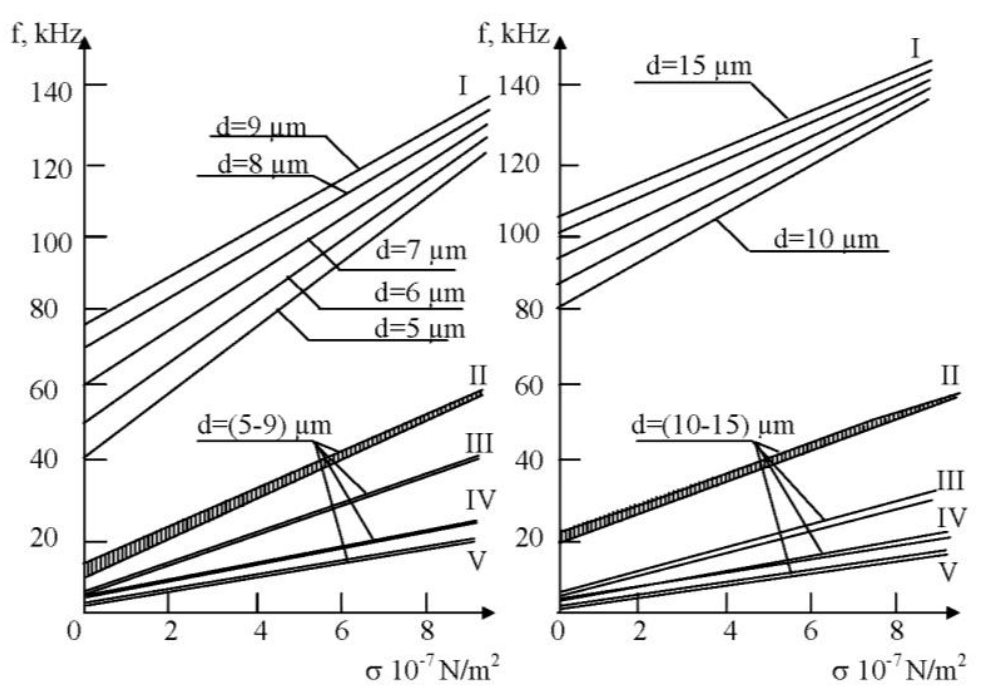

Fig. 6. The dependence of $f(\sigma)$ for FCs of different lengths and diameters: $\mathrm{I}-l=1 \mathrm{~mm}$; II $-l=2 \mathrm{~mm}$; III $-l=3 \mathrm{~mm}$; $\mathrm{IV}-l=4 \mathrm{~mm} ; \mathrm{V}-l=5 \mathrm{~mm}$

\section{Conclusions}

1. The research results confirm the promising of FMC application as sensitive element of vibration and frequency tensotransducer (sensor).

2. The metrological parameters of tensotransducer are determined by the linear density of the material, of the monocrystal's length, elasticity modulus and cross section.

3. The real measurement range of transducer significantly increases because the FMC retains the perfect elastic properties almost to the strength limit.
4. The tension deformation of FMC is the parameter that determines its own oscillations frequency and sensitivity to the measured parameter.

5 . The connections of output sensor tensosignal parameters with its own geometric dimensions and elasticity of the crystals, their mechanical stress, amplitude and mechanical oscillations frequency are established by the simulation.

6. The theory of the sensor is developed, which is based on the interconnection of mechanical and electrophysical properties in a semiconductor monocrystal, in which the direct transformation of mechanical oscillations into frequency is carried out.

\section{References}

1. Langdon R. M. Resonator sensors - a rewiew // Journal of Physics E: Scientific Instruments. 1985. Vol. 18, Issue 2. P. 103-115. doi: https://doi.org/10.1088/0022-3735/18/2/002

2. Packaged bulk micromachined resonant force sensor for high-temperature applications / Haueis M. et. al. // Design, Test, Integration, and Packaging of MEMS/MOEMS. 2000. doi: https://doi.org/10.1117/12.382278

3. Remtema T., Lin L. Active frequency tuning for micro resonators by localized thermal stressing effects // Sensors and Actuators A: Physical. 2001. Vol. 91, Issue 3. P. 326-332. doi: https://doi.org/10.1016/s0924-4247(01)00603-3

4. Sviličić B., Mastropaolo E., Cheung R. A MEMS Filter Based on Ring Resonator with Electrothermal Actuation and Piezoelectric Sensing // Procedia Engineering. 2014. Vol. 87. P. 1406-1409. doi: https://doi.org/10.1016/j.proeng.2014.11.706

5. Tunable Micro- and Nanomechanical Resonators / Zhang W.-M. et. al. // Sensors. 2015. Vol. 15, Issue 10. P. 26478 26566. doi: https://doi.org/10.3390/s151026478

6. Resonance Frequency Readout Circuit for a 900 MHz SAW Device / Liu H. et. al. // Sensors. 2017. Vol. 17, Issue 9. P. 2131. doi: https://doi.org/10.3390/s17092131

7. Silicon whiskers for sensor electronics / Druzhinin A. et. al. // Materials of XIII International conference Physics and technology of thin films and nanosystems. Ivano-Frankivsk, 2011. Vol. 1. P. 29.

8. Druzhinin A., Kutrakov A., Maryamova I. Tensoresistive pressure sensors based on filamentous silicon crystals for a wide range of temperatures // Bulletin of the Lviv Polytechnic National University. Electronics. 2011. Issue 708. P. 64-71.

9. Rak V., Baitsar R. A random errors estimation of the measuring generator of the resonance sensors // Sensors and systems. 2007. Issue 5. P. 16-21.

10. Baitsar R., Rak V., Zelisko Y. A temperature and pressure influence on the output frequency of the measuring generator of the resonance sensor // Measuring equipment and metrology. 2011. Issue 72. P. 88-93.

Дата надходження рукопису 31.07.2018

Baitsar Roman, Doctor of Technical Sciences, Professor, Department of Measuring Information Technologies, Lviv Polytechnic National University, S. Bandery str., 12, Lviv, Ukraine, 79013

E-mail: baitsar@ukr.net

Kvit Roman, PhD, Associate Professor, Department of Mathematics Lviv Polytechnic National University,

S. Bandery str., 12, Lviv, Ukraine, 79013

E-mail: kvit_rom@ukr.net 